\title{
SOBRE O FUNDAMENTO DOS DIREITOS HUMANOS SEGUNDO NORBERTO BOBBIO
}

\author{
ON HUMAN RIGHTS' GROUNDING ACCORDING \\ NORBERTO BOBBIO
}

\author{
Williard Scorpion Pessoa Fragoso'
}

\begin{abstract}
RESUMO: O presente trabalho lida com a contribuiçăo de Norberto Bobbio à tradiçáo crítica dos direitos humanos. Nesse sentido, apresenta suas principais objeçóes à noçâo de fundamento absoluto dos direitos humanos. E, por fim, procura enfatizar o que considera o aspecto mais original do trabalho, a falta de eficácia do fundamento abstrato às necessidades do mundo humano, bem como o campo hermenêutico que legou para a reflexâo acerca da teoria e prática em direitos humanos.
\end{abstract}

PALAVRAS-CHAVE: Bobbio; crítica; direitos humanos.

ABSTRACT: This paper deals with the contribution of Norberto Bobbio to the critical tradition of human rights. In this sense, it presents its main objections to the notion of absolute foundation of human rights. And finally, it seeks to emphasize what it considers to be the most original aspect of the work, the lack of effectiveness of the abstract foundation to the needs of the human world, as well as the hermeneutic field that left to the reflection on the theory and practice in human rights.

KEYWORDS: Bobbio; criticism; human rights.

\section{INTRODUÇÃO}

O que significa fundamentar? Grosso modo, podemos sintetizaras as noçōes de fundamento em duas: a primeira, como fundamento material à qual se atribui a noçấo de causa enquanto razâo de ser de algo, ou seja, das condiçôes materiais para o surgimento, origem, de um fenômeno; enquanto o segundo sentido lida com a noçấo de fundamento como ideal-argumentativo, ou seja, como conjunto de princípios puramente racionais e/ou suficientes para que, a partir deles, razóes entendidas enquanto motivos possam ser apresentadas justificadamente. Tanto cabem aqui as noçóes de fundamentaçáo tradicionalmente idealistas/metafísicas (Platăo, Agostinho, Leibniz, Hegel), quanto aos "contingentes" ou "fundamentos" empíricos (Aristóteles, Locke, Hume, Nietzsche), bem como o fundamento entendido como a justificaçâo racional-argumentativa própria aos "discursos concorrentes" contemporâneos - argumentaçôes sistemáticas que acabam por remeter aos endoxais aristotélicos e que disputam a prevalência ou a capacidade de gerar um consenso sobre determinado "ponto de vista", tema ou objeto.

Pós-doutorando no Programa de Pós-Graduaçăo em Direitos Humanos, Cidadania e Políticas Públicas (PPGDH) do Núcleo de Cidadania e Direitos Humanos (NCDH) da Universidade Federal da Paraíba (UFPB). 
Se sobretudo este último sentido tenta evitar o "mergulho em busca de um fundamento absoluto" metafísico e, com isso, parece muito contemporâneo, náo se deve esquecer de que, na contemporaneidade, permanecemos - ou retornamos à - na esfera endoxal aristotélica, das opinióes dos sábios/especialistas em dado assunto, como bem ponderou Enrico Berti.

No artigo "Presente e futuro dos direitos do homem", Bobbio remete a três estratégias para fundamentar valores; (i) a estratégia absoluta: consiste em deduzir o fundamento de um elemento conceitual estável, universal, inegável e independente da vontade dos homens, como, por exemplo, "a natureza humana"; (ii) a estratégia da evidência: concentra-se em apresentar sistematicamente dados auto-evidentes numa formulaçăo clara, dotada de forte apelo à concordância; e, por fim, (iii) a estratégia consensual: baseia-se na concordância historicamente dada em torno de um valor, "o que significa que um valor é tanto mais fundado quanto mais é aceito" (BOBBIO, 2003, p. 47).

Dadas as devidas proporçôes, essa sistematizaçâo conceitual geral dos modos de fundamentar assemelha-se à compreensăo apresentada por Ivan Domingues na obra O grau zero do conhecimento. Nas várias camadas históricas e conceituais que Domingues sobrepóe ao longo de sua compreensăo, ele estrutura as estratégias de fundamentaçấo nas ciências humanas em três blocos ao longo dos séculos: (i) estratégia essencialista, (ii) a estratégia fenomenista e (iii) a estratégia histórica. A primeira diz respeito, sobretudo, à antiguidade, à idade medieval e parte da modernidade. Dominantemente, nela prevalece a ideia de que há um fundamento imaterial definitivo, irresistível - mormente chamado absoluto -, de toda a realidade da vida (mundo das formas, Ser, Deus).

Na segunda estratégia discursiva, com a consolidaçăo e a independência das ciências na idade moderna, ${ }^{2}$ surge a exigência "naturalista" de critérios materiais e, com ela, a exigência "matemático-estatística" por princípios lógico-matemáticos que fundamentem e sistematizem dados empíricos capazes de gerar o conhecimento. Diante das limitaçóes das estratégias anteriores, a estratégia histórica "suspende" seus pressupostos e "faz sua aposta" nas "passagens", quer dizer, no campo do arbitrário e do consenso mediante forças da cultura vigente. Ela aposta nas mudanças, nas exigências, necessidades e percepçóes de cada tempo; ela aposta no relativismo urdido através dos tempos históricos (DOMINGUES, 1991, pp. 47-48).

O que é, entăo, fundamentar? Considerando o que foi afirmado anteriormente, náo parece absurdo asseverar que fundamentar significa, ao menos, apresentar razôes discursivamente. Se essas razōes săo meras crenças, se săo ou năo justificáveis, se elas sâo ou nâo verdadeiras e dependem de contextos históricos e culturais - ou năo -, é outra questăo. Com o perdâo da redundância, é uma questăo de "razoabilidade das razóes", isto é, dos critérios que tornam razoáveis as razóes. Sabemos que,

Para Domingues, no entanto, a episteme moderna - do século XVII ao século XIX - inclui pelo menos três estratégias discursivas em relaçăo à fundamentaçăo: "(a) uma, de tipo 'essencialista', no século XVII (a Ética, de Espinosa, e a Gramática, de Port-Royal); (b) outra, de tipo 'fenomenista', no século XVIII (o Espírito das Leis, de Montesquieu, e a Riqueza das Naçōes, de A. Smith); (c) outra, enfim, nem essencialista nem fenomenista, mas 'histórica', no século XIX (O Capital, de Marx, e a Gramática Comparada, de Bopp)” (DOMINGUES, 1991, p. 8). 
em filosofia, os problemas tendem a multiplicar-se: se năo estivermos contentes, poderíamos nos perguntar sobre os critérios que utilizamos para eleger nossos critérios de razoabilidade e, com isso, caímos no regresso epistêmico. Rudimentarmente, o regresso epistêmico acontece quando, após uma proposiçăo/afirmaçăo, perguntamos pela razăo de ser dela e, diante de uma resposta, seguimos pedindo razóes indefinidamente. Multiplicam-se as proposiçóes; indefinida e proporcionalmente, seguem-se os pedidos de justificaçăo. Independente das questôes epistemológicas por óbvio náo consideradas por Bobbio -, há desdobramentos curiosos na reflexâo de Bobbio sobre a questăo do fundamento último dos direitos humanos. Passemos aos desdobramentos.

\section{O FUNDAMENTO COMO RAZÃO DESCONCERTADA}

No início do ensaio "Sobre o fundamento dos direitos humanos", Bobbio nos aponta dois modos de tratar a questăo, a saber: a perspectiva do direito "que se tem" (relativo ao direito positivo) e a perspectiva do direito "que se gostaria de ter" (relativo ao direito racional ou natural em sentido restrito) (2004, p. 36). Identifica a perspectiva racionalista-essencialista com o procedimento filosófico e limita-a a este escopo. Trata, em seguida, de formular suas objeçôes à fundamentaçăo nos moldes do direito natural, enfrentando dois de seus principais dogmas, a saber: 1) a pretensâo de que os valores últimos (como a Verdade, o Bem, etc.) possam ser demonstrados e fundamentados; e 2) a pretensâo de que à demonstraçăo racional (através de teoremas) dos valores últimos seguir-se-ia, em caráter necessário e automático, sua efetivaçâo. Considerará, por último, a questăo dos direitos do homem a partir de sua "desejabilidade", reconhecendo, no entanto, que, embora desejados, perseguidos e reconhecidos, há grandes problemas de efetivaçâo.

Para Bobbio, encontrar um fundamento é o mesmo que "aduzir motivos para justificar a escolha que fizemos e que gostaríamos fosse feita também pelos outros [e que este] é um meio adequado para obter para eles um mais amplo reconhecimento" (2004, p. 37). É assaz claro que Bobbio apela para uma espécie de projeçâo subjetiva fraca de inspiraçâo kantiana ao tentar estabelecer um critério que passa pelo crivo do que "gostaríamos" a fim de obtermos maior reconhecimento/aceitaçăo. Notadamente, Bobbio năo enfrentará problemas específicos relativos à questâo do fundamento, como, por exemplo, o regresso epistêmico. Nâo é necessário. Ele o sabe. Ele trabalhará consciente de uma questăo de outra ordem: a "razăo pura" pouco pode diante da vontade.

Se é "da finalidade visada pela busca do fundamento [que] nasce o fundamento absoluto, ou seja, [d]a ilusăo de que, de tanto acumular e elaborar razóes e argumentos - terminaremos por encontrar a razăo e o argumento irresistível, ao qual ninguém poderá recusar a própria adesâo" (BOBBIO, 2004, p. 37), sendo dessa ilusâo acerca do "fundamento definitivo" que a razâo mostra-se impotente diante dos imperativos da vontade política, ou, se se preferir, diante das "razōes" movidas pelas paixôes políticas.

Consciente dessa ilusâo, Bobbio trata da questâo da fundamentaçấo absoluta trazendo à baila uma pretensăo que lhe subjaz: a pretensăo moderna da existência de uma essência no homem, ou seja, uma natureza abstrata imutável. Ambas, a ilusâo e a 
pretensăo, entregam-se à tentaçăo de que, intuindo "a verdade" acerca da existência/ condiçăo humana, podemos conhecê-la. Consequentemente, de modo inquestionável, quer-se assegurar a descoberta da natureza humana, e com isso assegurar, também, definitiva e irresistivelmente, seus direitos ínsitos.

Entretanto, o projeto moderno - herdeiro de Platăo e das filosofias medievais patrística e escolástica - esbarra em dificuldades insuperáveis. Aqui, as acuidade e originalidade de Bobbio quanto à percepçăo dos empecilhos văo além da sobriedade analítica. Inicialmente, ele nos apresenta quatro dificuldades segundo as quais a pretensăo a um fundamento absoluto é infundada (BOBBIO, 2004, pp. 37 e ss.). A primeira delas repousa na vagueza do termo "direitos humanos" e săo insuficientes em cinco níveis distintos e complementares, sendo: (a) tautológicas, ou seja, lidam dominantemente com definiçôes baseadas na mera sinonímia, sem nada acrescentar ou elucidar, apenas referindo termos/definiçôes para significar compreensivamente outros termos/definiçôes, à guisa de um dicionário; (b) utópicas (expressam o que se gostaria que fossem e náo o que săo); (c) avaliativas - e, portanto, abertas a interpretaçōes dependentes de perspectivas culturais, sociais, ideológicas distintas; (d) falsamente consensuais, caso em que as contradiçôes estariam ocultas e só apareceriam no caso de um conflito ou no momento de aplicaçáo dos direitos; e, por fim, (e) axiológicas, sendo que a fundamentaçăo dos direitos apelaria sempre para valores últimos, quer dizer, valores abstratos, auto-evidentes e inegáveis.

A segunda impossibilidade apontada por Bobbio parece tomar como base o caráter contingente da realidade - seja natural seja cultural - do qual năo se pode extrair nenhuma segurança, nenhuma certeza absoluta - a năo ser o paradoxal phantarhei (tudo muda) de Heráclito de Éfeso - e, portanto, nenhuma valoraçâo definitiva irresistível que gerasse um consenso irrestrito e instantâneo. Bobbio apela à relatividade histórica (2004, p. 38), para pontuar a ingenuidade da ideia do "fundamento absoluto" dos direitos humanos. Pondera, por conseguinte, que as prioridades, os interesses, as compreensôes, mudam com o correr dos anos, bem como de cultura para cultura. Destarte, para Bobbio, todo "fundamento" deveria se basear no relativismo, ou seja, ele deveria ser, estar aberto às contingências.

O argumento seguinte - o terceiro na ordem - opóe o caráter heterogêneo dos direitos à ideia do "fundamento absoluto"; ambas, primeira e segunda impossibilidades, baseiam-se no relativismo. Como os direitos possuem estatutos, pretensôes e eficácia diversos, conflitantes e/ou antinômicos, fica claro que seu fundamento náo pode valer-se de valores últimos, pois suas contradiçôes năo poderiam ser mediadas, nem ajustadas às necessidades factuais. Se os valores năo fossem "plásticos", moldáveis, "relativizáveis", a linguagem nâo seria dinâmica, espontânea e aberta às interpretaçôes; pelo contrário, ela seria pobre, estritamente lógica e, portanto, meramente operacional; inegociáveis, interditos em si e para si mesmos, os valores sobreporse-iam intransigentemente uns diante dos outros, o que impossibilitaria qualquer comunicaçâo. Nada disso seria mais contrário à condiçấo humana, à liberdade e à democracia, do que tal concepçăo concomitante de valor e linguagem.

Como exemplos limites, Bobbio mostra o contraste entre o direito fundamental de uma categoria e o direito igualmente fundamental de outra: da liberdade do artista versus a liberdade do público; apresenta, ainda, a oposiçấo entre direitos que se tornam inquestionáveis e irresistíveis: "a realizaçăo integral de uns impede a realizaçâo 
integral dos outros; quanto mais aumentam os poderes dos indivíduos, tanto mais diminuem as liberdades dos mesmos indivíduos" (BOBBIO, 2004, p. 41).

Finalizando a série, Bobbio apresenta a quarta e última objeçăo. Estrategicamente, ele questiona: mesmo se a fundamentaçâo absoluta dos direitos humanos fosse possível, ela garantiria rápida e eficazmente o reconhecimento e a realizaçấo dos direitos humanos? (BOBBIO, 2004, p. 43). Em que se baseia esta pretensăo de que um fundamento absoluto garantiria uma efetivaçâo instantânea dos direitos humanos? A questâo náo é óbvia e carrega os desdobramentos mais originais e contundentes do autor. Para Bobbio, a pretensăo de uma fundamentaçâo definitiva dos direitos humanos (BOBBIO, 2004, p. 42) estaria amparada em dois dogmas do racionalismo ético jusnaturalista. O primeiro dogma do racionalismo ético (a confiança e a crença nos poderes irrestritos da razáo) considera possível a demonstrabilidade e a autofundamentaçâo dos valores últimos através da razâo; enquanto o segundo dogma (o primado e a superioridade racional perante a realidade) reza que, demonstrados os "teoremas" - portanto seu caráter racional e necessário -, sua realizaçăo efetiva estaria assegurada.

Por conseguinte, também os direitos estariam assegurados. Se assim năo o fosse, seria extremamente contraditório, o que, nesse caso específico, implicaria em um resultado antitético, paradoxal, antirracional: a razáo mostraria de forma matematicamente precisa - conforme a linguagem oculta da natureza - o que deveria ser feito, porquê fazê-lo e os meios para tanto.

Contudo, na prática, a realidade "necessária" apontada pela razăo naufragaria logo após deixar o porto. A crença na garantia de efetivaçâo necessária dos direitos humanos decorrentes da fundamentaçăo racional, bem como na harmonia entre razâo e natureza săo, nesse caso, tributárias do postulado lockeano segundo o qual a fonte da essência do mundo e do homem é uma só: Deus (LOCKE, 2007, pp. 105-109).

As consequências emergem da última objeçâo de Bobbio: a própria realidade trata de pôr em xeque a pretensăo de uma fundamentaçăo absoluta dos direitos humanos. A coerência entre a racionalidade divina atribuída ao mundo e aquela atribuída ao humano é contestada e desmentida cabalmente pela estruturaçăo contingencial partilhada tanto do mundo das paixóes políticas quanto pelo mundo natural. Forçosamente, sabe-se que, mesmo que algo seja demonstrado como verdadeiro, isso nâo gera sua aceitaçâo e/ou realizaçâo instantâneas. Há múltiplos e variáveis fatores que condicionam a aceitaçăo de algo, seja verdadeiro ou năo. Logo, diante do inseparável abismo que, por vezes, mostra-se entre aquilo que deve ser e o que é, ou seja, além da impotência da razâo, dos impasses políticos, estamos diante de limitaçōes que dizem respeito à economia, ou melhor, à economia política.

Nesse sentido, mesmo que houvesse um fundamento absoluto-racional, no momento da efetivaçáo dos direitos humanos, esse fundamento de nada - ou muito pouco - adiantaria. O simples desvelamento deste fundamento năo funcionaria como um gatilho que dispararia as potências metafísicas adormecidas, imanentemente, no mundo. Ele nâo colocaria instantaneamente em movimento todas as condiçóes, boa vontade e açôes para que os direitos humanos realizassem sua plenipotência. Aliás, seja um fundamento do tipo lockeano, seja do tipo heideggeriano - afirmado como liberdade, como campo aberto das possibilidades (HEIDEGGER, 2007, pp. 123-127) -, 
isto é, seja como for, nenhum brilhantismo puramente, isoladamente, racional conseguiria trazer o reino dos céus à terra.

Ainda assim, mesmo de posse do fundamento absoluto, estar-se-ia diante de seu caráter mais problemático, mostrado por Bobbio com brilhantismo: possuir-se-ia tal fundamento, mas ele de nada adiantaria. Impasses de toda ordem - dos "retóricos" aos político-econômicos - tratariam de "marinar" ad infinitum quaisquer açóes e propostas concretas.

\begin{abstract}
Por isso, agora, năo se trata tanto de buscar outras razóes, ou mesmo (como querem os jusnaturalistas redivivos) a razăo das razōes, mas de pôr as condiçōes para uma mais ampla e escrupulosa realizaçáo dos direitos proclamados. Decerto, para empenhar-se na criaçăo dessas condiçóes, é preciso que se esteja convencido de que a realizaçáo dos direitos do homem é uma meta desejável; mas náo basta essa convicçăo para que aquelas condiçôes se efetivem. Muitas dessas condiçōes [...] năo dependem da boa vontade nem mesmo dos governantes, e dependem menos ainda das boas razóes adotadas para demonstrar a bondade absoluta desses direitos: somente a transformaçăo industrial num país, por exemplo, torna possível a proteçâo dos direitos ligados às relaçôes de trabalho. (BOBBIO, 2004, p. 14)
\end{abstract}

A introduçăo da questăo do desenvolvimento industrial (técnico-científico) e suas implicaçôes ligadas ao trabalho faz com que Bobbio atinja o momento mais sutil de sua reflexăo. A industrializaçăo năo é algo que dependa unilateralmente dos governos. Porém, está imbricada fortemente nas políticas públicas governamentais e/ou de órgáos internacionais como o Banco Mundial. Desde Marx, o aspecto econômico de dada realidade năo pode ser desvinculado do aspecto político. Entretanto, para fins metodológicos, deve-se admitir tal separaçăo, que consiste basicamente em distinguir a "boa vontade política" do desenvolvimento econômico de um país.

Se há má fé na política, o "fundamento irresistível", por mais racionalmente bem urdido que seja, é praticamente certo que năo levará ninguém a convencer-se das "vantagens" práticas da boa conduta. O fundamento também năo ajudará nenhum governo a cobrir décadas e décadas de erros nas políticas de desenvolvimento industrial, nem tampouco pode criar condiçóes naturais favoráveis para qualquer atividade fabril que dela necessite.

Entretanto, é o "gênio" humano e suas astúcias que estăo em jogo aqui. Se fosse sua "vontade", moveria o que fosse necessário para que os direitos humanos ultrapassassem as barreiras do reconhecimento formal por parte dos países. O que está em jogo é a velha disputa entre "vontade" e "razăo", ou melhor, entre "razăo pura" e as "razōes" dos jogos de poder e política. E ter trazido à baila este confronto - ainda que rapidamente -, torna a reflexăo de Bobbio ainda mais rica. Entre as insuficiências da pretensăo do fundamento absoluto ao ardiloso - e nada simples - universo político, as cartas da disputa entre vontade e racionalidade estăo postas na mesa.

Lógica e epistemologicamente, năo é impossível que se encontre um ou mais de um fundamento para os direitos humanos; năo há nenhum impedimento nessa direçăo. Contudo, já se pode perceber que, no que concerne aos direitos humanos, năo é essa a questăo mais relevante. Analogamente, é possível que esse(s) fundamento(s) possua(m) qualidades suficientes para sustentar-se epistemologicamente como 
proposiçōes erigidas a partir de crenças verdadeiras justificadas. Porém, năo é o quadro teórico do qual de dispóe até o momento. Os recursos argumentativos dos quais se dispōe, da hermenêutica à fenomenologia, da metafísica tradicional à epistemologia contemporânea, năo conseguiram "vencer" o regresso epistêmico. No máximo, com o coerentismo e infinitismo ${ }^{3}$ epistêmicos năo se consideraria mais tal regresso como um problema, mas como parte natural da estrutura epistêmica.

Talvez, se se resolvesse a questâo da fundamentaçâo dos direitos humanos a partir de outro paradigma - e seus problemas correlatos -, poder-se-ia ter um elemento favorável que impulsionasse a efetivaçăo. É sabido que a resoluçăo de problemas filosóficos, de fundamentaçăo ou nâo, nâo implica necessariamente na soluçăo das questôes práticas de efetivaçăo e gozo dos direitos - assim como a compreensâo racional nâo implica na determinaçăo da vontade -; contudo, a resoluçăo da questâo do fundamento poderia oferecer um forte apelo argumentativo fosse de ordem sentimental, fosse de ordem racional.

\section{CONCLUSÃO: DIREITOS HUMANOS, UM CAMPO HERMENÊUTICO FÉRTIL}

Independente da definiçâo ou redefiniçâo da tarefa da fundamentaçâo - e quais os (des)níveis de importância que ela assume ou assumirá -, fica-se outra questăo - provocaçăo: qual é a necessidade de fundamentar? E se o fundamento já estiver posto e, assim, náo haja necessidade de fundamentar? Se, por outro lado, o fundamentar, no caso dos direitos humanos, seja o fazer, a práxis? Nesse caso, fundamentar seria trabalhar pela estabilidade e crescimento da cultura dos direitos humanos. $O$ fundamento, o fenômeno dos direitos humanos - sua vasta e rica miríade de nuances histórico-culturais - seria muito frágil e dependeria da açăo de fundamentar.

\footnotetext{
Tanto o coerentismo quanto o infinitismo sấo correntes epistemológicas que năo consideram o regresso epistêmico uma ameaça ao conhecimento. Para o coerentismo, o conhecimento forma-se pela uniáo de proposiçôes coerentes entre si que estabelecem, ao longo do tempo, um conjunto sistemático de crenças/ proposiçóes. Se novas crenças aparecerem, elas se unirăo às já existentes. Se elas divergirem fortemente, o conjunto pode sofrer uma revisăo e passar por uma reformulaçáo parcial ou completa. Se as novas crenças năo forem fortes o suficiente para objetar a estrutura já existente, elas năo sáo necessariamente excluídas; podem ficar no conjunto, "flutuando", até que se tornem robustas com a adesâo de novas proposiçôes que as corroborem ou, entăo, permanecem disponíveis sem comprometer nem ameaçar o "sistema" de crenças existentes. Já o infinitismo trabalha com a ideia de que o conhecimento é dinâmico e gera novas proposiçôes e crenças ininterruptamente. Essas crenças/proposiçóes agregam-se e ordenamse em conformidade com as exigências e necessidades do estágio de desenvolvimento do conhecimento; elas podem ser mais ou menos coerentes. A ideia fundamental aqui é a noçăo de que o conhecimento năo precisa de crenças básicas, de crenças fundamentais, absolutamente seguras, que fundamentem as demais crenças năo-básicas. As crenças/proposiçōes apoiam-se mutuamente e podem multiplicar-se indefinidamente sem problema algum. (MOSER, DWAYNE, TROUT, 2009, pp. 85-105)
} 
Para Eduardo Rabossi, ${ }^{4}$ epistemólogo e jurista argentino, foi Bobbio quem tratou a questăo da justificaçăo absoluta dos direitos humanos e a questáo da dimensâo histórica do consenso que começa a ser claramente delineada a partir da Declaraçáo de 1948 com mais lucidez. Além disso, para Rabossi:

[...] Norberto Bobbio - aquien se deben páginas sencillas, breves y extremadamente lúcidas sobre el tema de los derechos humanos - ha señalado la existencia de un movimiento dialéctico que comienza con la universalidad abstracta de los derechos naturales, pasa a la particularidad concreta de los derechos positivos nacionales, y termina con la universalidad ya no abstracta, sino concreta, de los derechos 
direitos humanos e a identificaçăo de seu elemento crítico no que respeita ao binômio teoria e prática.

Rabossi trabalha a partir da perspectiva de que a "questâo do fundamento" está ultrapassada sejam quais forem suas dificuldades inerentes. Diante das violaçôes, problemas, falhas nos sistemas de proteçăo dos direitos humanos, é imperativo trabalhar no sentido de ampliar, fortalecer e propagar a cultura dos direitos humanos e sua influência; também trabalhar para superar oposiçôes equivocadas como a já tradicional oposiçâo entre teoria e prática.

Na verdade, pensadores do porte de Bobbio, Rabossi e Rorty - respectivamente, um historicista, um neopositivista e um pragmatista - esforçaram-se para recolocar a filosofia prática - e com ela os direitos humanos - num âmbito desafiador à reflexăo: a esfera dialética (à moda antiga) da dóxa e do mundo fenomênico. Esfera que năo só serviria para orientar o universo da filosofia prática, mas também funcionaria como modelo para rever criticamente todo o habitus da tradiçăo de pensamento ocidental.

Tradiçăo essa que tem se esforçado em modelar o mundo através do pensamento e năo de compreender e modelar o pensamento a partir do mundo, ou melhor, de compreender que, antes de qualquer esfera e consciente de suas especificidades, o pensamento é parte de um corpo que está circunstanciado no mundo. $O$ pensamento, enquanto parte do mundo, molda-se enquanto molda o mundo no qual vive, do qual é parte e do qual depende.

Nâo é estranha a distinçăo aristotélica entre ciências teoréticas (ou contemplativas), ciências práticas e produtivas. As primeiras objetivam o conhecimento em si mesmo, "autônomo", e tratam de "objetos" que existem, independentemente, da açâo e da vontade dos homens; sâo objetos de contemplaçăo. As ciências teoréticas sâo: a filosofia ou teologia, a matemática e a física. O método apodítico é seu método por excelência: o silogismo apodítico é formado por premissas que possuem validade independente da vontade ou da açăo de quem lida com elas; trata-se de premissas verdadeiras por si mesmas; por definiçăo, o método apodítico está livre de dúvidas; é o método da certeza.

Já as ciências práticas săo aquelas que constituem um conjunto de saberes cujos "objetos" dizem respeito à esfera da vontade/açăo e do fazer humanos e que objetivam um conhecimento como um guia de conduta (ROSS, 1987, p. 71). ${ }^{5}$ As ciências práticas (práxis: política, ética, retórica, etc.) possuem um fim em si mesmas; fim esse que estrutura agente, açăo e "objeto" na realizaçăo do fim (telos). Enfim, tem-se as ciências produtivas, isto é, relativas à poiesis (açâo fabricadora, arte, técnica: navegaçấo, arquitetura, pintura, poesia, agricultura, etc.) que năo possuem um fim em si mesmas, quer dizer, nas quais năo ocorre uma "coincidência" entre açăo, agente, objeto e a finalidade.

O método dialético é o método próprio das ciências práticas; a esse método corresponde o silogismo dialético cujas premissas sáo endoxais, quer dizer, caracterizadas

\footnotetext{
5 "Mas se é evidente que o homem é a origem de suas próprias açōes e se nâo somos capazes de relacionar nossa conduta a quaisquer outras origens que năo sejam as que estáo dentro de nós mesmos, entáo as açôes cujas origens estāo em nós devem também depender de nós e ser voluntárias". (ARISTÓTELES, 1996, p. 159)
} 
por sua notoriedade e aceitaçăo gerais; notoriedade e aceitaçăo que năo dependem da mera opiniáo, mas da opiniăo autorizada que emana da experiência em geral, da reflexâo e das discussōes (BERTI, 1998).

Com as posturas de Bobbio, Rabossi e Rorty, năo há, portanto, apenas um retorno à esfera da práxis dentro de suas pertinência e exigências próprias já indicadas por Aristóteles. Apesar das diferenças, elas compartilham de uma visăo de filosofia pautada pelo mundo que temos diante de nós e de suas questōes mais prementes. Com essa visâo, ocorre uma virada "naturalizante", em que a clivagem pensamento-mundo também perde o sentido. $O$ pensamento assume seu caráter mundano; é naturalizado. Começamos a lidar com paradigma realisticamente radical em termos filosóficos. Aqui năo há garantias extramundanas: que os direitos humanos continuem existindo e "funcionem" progressivamente mais e melhor; depende unicamente de nós, do que fazemos, de como fazemos, do que pensamos e de como pensamos e vivemos.

Emblematicamente, Berti nos dá uma ideia bastante razoável do fenômeno dos direitos humanos pensados na esfera endoxal aristotélica. Considerar Bobbio, Rabossi, Rorty, Putnam e Quine vinculados, certamente nos conduzem a uma ampliaçăo e uma ressignificaçấo de uma tradiçăo de pensamento que converge para uma unidade sem negaçăo da pluralidade. Sem se furtar às contradiçôes, Berti pondera:

Pois bem, minha tese é a de que hoje a funçăo daquilo que Aristóteles chamou de éndoxa pode ser desenvolvida pelos direitos humanos, isto é, pelas enunciaçóes contidas nas grandes declaraçóes dos direitos, tais como as cartas constitucionais dos vários Estados e as declaraçóes das grandes organizaçôes internacionais, ou seja, a ONU, o Conselho da Europa, a Organizaçăo para a Unidade Africana, a Organizaçăo da Conferência Islâmica, etc. Com relaçăo às cartas constitucionais dos vários Estados năo há dúvida de que elas, desde que entraram em vigor, receberam a aprovaçấo e, portanto, o consenso da maior parte dos cidadâos ou dos seus representantes e devem ser aceitas, a princípio, pelos mesmos cidadăos (BERTI, 2006, p. 141).

A dimensăo concreta do fenômeno dos direitos humanos náo está e năo pode ser posta em dúvida. Quaisquer problemas teóricos - sejam ou náo de ordem ontológica - devem ser levados ao interno do fenômeno e ali tratados. Qualquer outra atitude teórica revelaria, muito provavelmente, uma impostura epistemológica. Seria um ganho incontestável, situar a teoria dos direitos humanos no campo endoxal que lhe é próprio, evitando o habitus metodológico da metafísica tradicional. Berti segue refletindo que:

Por essas razóes, acredito que as declaraçóes dos direitos humanos sejam hoje compartilhadas, senáo por todos, certamente pela maioria dos homens e pelas pessoas competentes, que sâo os representantes das populaçóes dos Estados, ou seja, os homens políticos, ou pelo menos pela maioria deles e pelos mais proeminentes. Estes correspondem perfeitamente, portanto, à definiçáo que Aristóteles deu dos éndoxa. Nâo é válido repetir, contra eles, a objeçăo continuamente feita de que os direitos humanos, embora proclamados por todos, săo muitas vezes desprezados pelos próprios Estados que compōem as Naçóes Unidas ou pelos homens políticos, por exemplo, os ditadores, que operam no interior dos Estados. (BERTI, 2006, p. 143) 
Com clareza, percebe que, além de um consenso considerável, a estratégia do constrangimento e da sensibilizaçăo (RORTY, 2005) diante de uma compreensâo acerca do que é moralmente reprovável ou náo começa a ser posta em funcionamento a partir do fenômeno dos direitos humanos. A cultura dos direitos humanos, com todos os seus problemas, desdobra uma conquista importante, embora năo livre de riscos: uma nova compreensáo, um novo olhar entre os agentes políticos dos mais diversos graus, do cidadăo ao governante. Para Berti:

[...] é também um fato que aqueles que violam os direitos humanos muitas vezes negam-no ou encobrem que o cometem, ou seja, náo tentam justificar publicamente tais violaçóes: praticam-nas de fato, mas recusam energicamente a imputaçăo de têlas praticado. Há nisso certamente muita hipocrisia, mas também o reconhecimento de que náo se pode publicamente tomar uma posiçấo contrária aos direitos humanos, uma vez que esta posiçáo seria impopular e provocaria uma perda de consenso que poderia enfraquecer quem a sustenta. Portanto, inclusive os que violam os direitos humanos reconhecem implicitamente que eles săo amplamente compartilhados. Tal reconhecimento confere um prestígio indubitável aos direitos humanos ao qual, com certeza, as posiçóes opostas ou divergentes năo podem aspirar. (BERTI, 2006, pp. 145-147)

Sem dúvida alguma, a reflexăo de Bobbio insere-se neste campo endoxal de Aristóteles revisitado por Berti. Ela contribuiu - e ainda contribui - enormemente para que se possa pensar o mundo abertamente, quer dizer, sem forçá-lo à "razâo pura", apartada, monolítica, hierarquicamente vertical e totalitária, superior ao contingente, ao diverso, ao natural. Nesse sentido, o campo hermenêutico do fenômeno dos direitos humanos convida constantemente a refletir, em nossa animalidade, sobre nossa humanidade, ou melhor, sobre o processo de humanizaçăo de nossa animalidade; projeto/processo empreendido ao longo da história.

Vista com argúcia e gênio por Bobbio, a fragilidade dos direitos humanos, inscreve-se nesse processo e aponta para a necessidade de, no percurso de aprender a ser humano, assumirmos a fraternidade entre razăo, vontade e sensibilidade. Evitar-seia a sobreposiçâo em luta destrutiva, do conflito de má-fé; por outro lado, criar-se-ia, um campo para a relaçấo harmoniosa que năo precisaria prescindir de suas dissonância e tensăo durante o caminho. O esforço por relaçóes simétricas entre todos os seres humanos em relaçáo aos direitos fundamentais é o resultado de um processo de gradual eliminaçăo de discriminaçôes, e, portanto, de unificaçăo daquilo que foi sendo reconhecido como idêntico: traços comuns aos humanos acima de qualquer diferença de sexo, raça, religiăo, etc. (BOBBIO, 2000, p. 492).

Salve Norberto Bobbio! Salve a crítica aos direitos humanos!. 


\section{REFERÊNCIAS BIBLIOGRÁFICAS}

ARISTÓTELES. Ética a Nicômaco. Brasília: UnB, 1985.

Política. Săo Paulo: Nova Cultural, 1999.

BERTI, Enrico. A atualidade dos direitos humanos. Perspectiva Filosófica, v. I, n. 25, 2006, pp. 135-152.

As razōes de Aristóteles. Sáo Paulo: Loyola, 1998.

BOBBIO, Norberto. A era dos direitos. Rio de Janeiro: Campus, 2004.

. 0 problema da guerra e as vias da paz. Sáo Paulo: Unesp, 2003.

. Teoria geral da política: A filosofia política e a liçăo dos clássicos. Rio de Janeiro: Campus, 2000.

DOMINGUES, Ivan. 0 grau zero do conhecimento. Săo Paulo: Loyola, 1991.

HEIDEGGER, Martin. A essência do fundamento. Ediçăo bilíngue. Lisboa: Ediçōes 70, 2007.

QUINE, Willard Van Orman. De um ponto de vista filosófico. Sáo Paulo: Unesp, 2011. 